\title{
Impacts of mesic and xeric urban vegetation on outdoor thermal comfort and microclimate in Phoenix, AZ
}

Jiyun Song ${ }^{a}$ and Zhi-Hua Wang ${ }^{a 1}$

${ }^{a}$ School of Sustainable Engineering and the Built Environment, Arizona State University, Tempe, AZ 85287, USA

${ }^{1}$ Corresponding author; Tel: +1-480-727-2933; Fax: +1-480-727-0557; Email: zhwang@asu.edu 


\section{Abstract}

Urban vegetation is an effective way in mitigating excessive heat and improving the outdoor thermal environment for residents in cities via evaporative cooling. Different urban vegetation forms (mesic or xeric) alter surface energy and water budgets in different ways, which is further complicated by interactions with buildings and anthropogenic controls. Mesic vegetation such as lawns reduces urban temperatures by evaporative cooling but requires large amounts of water for continuous irrigation. Xeric vegetation such as shade trees reduces urban temperatures mainly through radiative shading and has low water demand. The objective of this study is to investigate the impacts of different vegetation forms on microclimate in a hot desert city - Phoenix, AZ. We applied an advanced urban canopy model coupled with a single-column atmospheric model to simulate urban boundary layer dynamics over different landscaping scenarios with different combinations of mesic and xeric vegetation forms. We subsequently compared the urban land surface temperatures, near-surface air temperatures, outdoor thermal comfort in the urban canopy layer, as well as atmospheric dynamics (temperature, humidity) in the overlying boundary layer for a set of different scenarios.

Keywords: Evapotranspiration; Mesic and xeric landscapes; Radiative shading; Thermal comfort; Urban boundary layer; Urban vegetation 


\section{Introduction}

Urban vegetation has been applied at different spatial scales to extend green spaces in urban areas by constructing public parks, residential yards, and rooftop gardens, etc. [1-3]. Vegetated spaces in urban areas are effective in mitigating the urban heat island (UHI) effect [4-6] and essential to improve people's living environment ecologically and aesthetically $[7,8]$. Urban vegetation can modify the urban surface energy and water balance through increasing latent heat fluxes through evapotranspiration (ET), reducing net energy absorption by canopy shading, and reducing net heat storage with permeable soils [9]. Mesic vegetation (e.g. urban lawns) is effective to reduce surface and near-surface air temperatures compared with surrounding nonvegetated areas due to increased evapotranspiration, small heat capacity, and radiation attenuation of leaves [10,11]. However, the cooling effect of grass requires large amounts of water for irrigation, which is a sustainability challenge especially for arid and semi-arid cities $[12,13]$. Xeric vegetation (such as low-water demanding shade trees), on the other hand, offers an attractive alternative to ameliorate urban heat problems [14]. Roadside trees improve thermal comfort, owing to decreased shortwave radiation by direct shading and decreased longwave radiation with reduced surface temperature $[10,15]$.

In hot seasons of arid regions, people are likely to experience thermal discomfort and heat stress due to intensive solar radiation and low relative humidity [16]. The heat stress can be relieved by urban vegetation in different ways: (i) grass can add humidity into the air and reduce sensible heat and longwave emission, and (ii) trees can directly shade a pedestrian and limit reflected radiation in the street canyon [17]. In the meanwhile, different vegetation types require different amounts of water for irrigation. Mesic urban landscape usually requires irrigation by sprinklers with high water demand; while xeric trees are often irrigated by individual drip 
emitters with low water demand [18]. Therefore, the vegetation type needs to be carefully selected in urban planning to achieve the balance between thermal comfort and water consumption. In addition, since urban vegetation modifies the surface energy and water budgets, these modifications may be further reflected in the dynamics of the overlying atmospheric boundary layer (ABL) due to land-atmospheric interactions [19].

In this paper, we selected a hot desert city - Phoenix, Arizona as the study area. Located along the northeast of the Sonoran Desert, Phoenix has warm and dry desert climate with a high temperature of at least $38^{\circ} \mathrm{C}$ for more than 100 days per year and a low average precipitation of $203 \mathrm{~mm}$ annually $[13,20]$. With large number of clear and calm days, Phoenix is more likely to experience the heat and water stress [21]. According to City of Phoenix Water Services Department, Phoenix is confronting with a number of water risks to its long-term supply due to lack of water sources, continued rapid growth of population, high demand of water consumption induced by the UHI, and uncertainty of future climatic conditions [21-24]. Residential water usage accounts for two-thirds of the total water demand in the Phoenix city, of which $50 \%$ $75 \%$ is used by single-family units. The majority of water consumption by single family units is for landscaping and other outdoor uses [13].

Despite the increasing research effort devoted to the study of urban vegetation on the environmental sustainability, in particular, UHI and heat stress mitigation, most studies are exclusively focused on the surface and near-surface temperatures $[25,26]$ as well as outdoor thermal comfort in a street canyon or around a single building [17,27,28]. For a more comprehensive understanding of the impact of urban vegetation on local microclimate via landatmosphere interactions, it will be useful if the dynamics of urban boundary layer is included in numerical models. In this study, we investigate the coupled heat and water transport in the soil- 
land-atmosphere continuum, with more extensive vertical dimension, viz. from subsurface to the atmospheric boundary layer (ABL, $\sim 1-3 \mathrm{~km}$ in a desert city). Towards this objective, we will adopt a coupled urban canopy-atmosphere model [19] to study the impacts of urban vegetation forms on local microclimate in the study area. The coupled model constitutes of an advanced urban canopy model (UCM) with realistic representation of mesic grass and shade trees in street canyons and a classical single column model (SCM) for ABL physics. The details of the model physics will be introduced in Section 2. The coupled UCM-SCM framework will be used to simulate different landscaping cases with different combination of mesic and xeric vegetation in the study area. Then the simulated results will be intercompared with dynamic indicators including the urban surface and near-surface temperature, and outdoor thermal comfort in the urban canopy layer, as well as the predicted temperature and humidity in the convective mixed layer and ABL height, presented in Section 3.

\section{Urban Land-Atmospheric Modeling}

\subsection{Urban land surface processes}

The accurate predictions of urban land surface processes are of primary importance for simulating urban land-atmosphere interactions [19]. In this study, an advanced UCM with realistic representation of urban design and improved parameterization of urban surface energy and water budgets are adopted [29]. Here, the urban area is represented by the common twodimensional (2D) street canyon (the "big canyon" representation) with the consideration of both grass and trees on the street [29,30], as shown in Fig. 1. It is noteworthy that recent studies of urban microclimate adopted three-dimensional (3D) representation of urban geometry in order to resolve the detailed physics of flow in street canyons using computational fluid dynamics (CFD) 
[48-50] or local climate zone (LCZ) models [51]. It was found that the 3D canyon geometry facilitates the numerical simulation of physics of turbulence in the canopy layers, particularly at building-resolving to neighborhood scales. On the other hand, the current study, by coupling the UCM and atmospheric dynamics, focuses to capture the coupled energy and moisture (humidity) transport at larger (city to regional) scales, to provide useful information for more sustainable urban planning strategies. A detailed representation of building geometry at these scales will be quite costly using CFD models.

The governing energy balance equation on the urban land surface is given by [31]

$$
R_{n}+A_{F}-G_{0}=H_{s}+L E_{s}
$$

where $R_{n}$ is the net radiation $\left(R_{n}=S_{d}+L_{d}-S_{u}-L_{u}\right.$, with $S$ and $L$ denoting shortwave and longwave radiation components, and the subscript $d$ and $u$ indicating downward and upward directions, respectively), $A_{F}$ is the anthropogenic heat and moisture fluxes, $G_{0}$ is the conductive heat flux into ground, $H_{s}$ and $L E_{s}$ are the turbulent sensible and latent heat fluxes arising from urban surface layer. The left hand side expression of Eqn. (1), i.e. $\left(R_{n}+A_{F}-G_{0}\right)$ is called the available energy, which is partitioned into turbulent fluxes $\left(H_{s}\right.$ and $\left.L E_{s}\right)$ at the land surface, as shown on the right hand side. Different urban vegetation forms will alter surface energy balance in different ways: the grass cools the urban surface by altering surface energy partitioning, i.e. increasing latent heat fluxes and reducing sensible heat fluxes; the tree cools the urban surface by reducing the total available energy, specifically the net radiation through radiative shading.

\subsubsection{Surface energy balance for mesic urban vegetation}


The total sensible $\left(H_{s}\right)$ and latent heat $\left(L E_{s}\right)$ fluxes arising from the urban surface is the aggregation of heat fluxes arising from individual urban facets in the canopy layer, viz. roofs, walls, and ground surfaces,

$$
\begin{gathered}
H_{s}=\frac{x_{R}}{x_{R}+x_{G}} H_{R}+\frac{x_{G}}{x_{R}+x_{G}} H_{c a n} \\
L E_{s}=\frac{x_{R}}{x_{R}+x_{G}} L E_{R}+\frac{x_{G}}{x_{R}+x_{G}} L E_{c a n}
\end{gathered}
$$

where $x_{R}$ and $x_{G}$ are the roof width and road width respectively, $H_{R}$ and $L E_{R}$ are the sensible and latent heat fluxes arising from roofs, $H_{c a n}$ and $L E_{c a n}$ are the sensible and latent heat fluxes arising from street canyons, which are then given by

$$
\begin{gathered}
H_{\text {can }}=\frac{2 x_{W}}{x_{G}} H_{W}+H_{G} \\
L E_{\text {can }}=L E_{G}
\end{gathered}
$$

where $x_{W}$ is building height, $H_{W}$ and $H_{G}$ are the sensible heat fluxes from wall and ground surfaces respectively, $L E_{G}$ is the latent heat fluxes from ground surface. Since we assume no vegetation cover on walls, the latent heat fluxes from ground vegetation (i.e. lawn) is the only source of latent heat flux in the street canyon.

The sensible heat flux from a generic canyon facet (i) is parameterized as [32,33],

$$
H_{i}=\frac{c_{p} \rho_{a}\left(T_{i}-T_{c a n}\right)}{r_{a}},
$$

where $\rho_{a}$ is the air density, $c_{p}$ is the specific heat capacity of the air, $T_{i}$ is the surface temperature of an canyon facet $i$ ( $i=G, W, R)$, which can be ground, wall, or roof, $T_{c a n}$ is air temperature in the street canyon, $r_{a}$ is the aerodynamic resistance between canyon facets and air. The latent heat flux from ground (specifically lawn) is parameterized as [29] 


$$
L E_{G}=\beta_{e} \frac{L_{v} \rho_{a}\left(q_{G}^{*}-q_{c a n}\right)}{r_{a}+r_{s}},
$$

where $L_{v}$ is the latent heat of water vaporization, $q_{G}{ }^{*}$ is the saturated specific humidity above grass surface, $q_{c a n}$ is the specific humidity of the air in the urban canyon, $r_{s}$ is the stomatal resistance, and $\beta_{e}$ is a potential evaporation reduction factor, which reflects the constraint on actual evaporation by soil water availability and can be parametrized as [34]

$$
\beta_{e}=\frac{W-W_{r}}{W_{s}-W_{r}}
$$

where $W$ is the volumetric soil water content, and $W_{s}$ and $W_{r}$ are the saturated and residual soil water content respectively. For well-irrigated lawns, $\beta_{e}$ is close to 1 since the soil water will always be saturated with $W=W_{s}$.

Driven by meteorological variables in the surface layer (slightly above rooftop level but lower than the bottom of the mixed layer), i.e. solar radiation, air temperature, air humidity, wind speed, etc., the UCM is capable of predicting the energy and water transport processes on the urban surface, such as surface temperature, net radiation, sensible and latent heat fluxes as well as soil moisture. For model evaluation, we use surface energy fluxes measured at an eddy covariance (EC) tower, located at Maryvale, west Phoenix (33.48 N, 112.14 W) [35] (Fig. 2a, see Table 1 for more site information). In addition, Table 2 lists the detailed instrumentation of all three sites, with all sensing instruments pre-calibrated by manufacturers before deployment and subject to regular on-site calibration. The EC tower has a height of $22.1 \mathrm{~m}$ and measures meteorological variables with $10 \mathrm{~Hz}$ frequency. The raw $10 \mathrm{~Hz}$ tower data were collected by Campbell high frequency data logger and post-processed through the EdiRe software platform. Prior to analysis, the data quality was controlled through signal de-spike, natural wind coordinate alignment, sensor lag offset, frequency response correction, etc. [35]. Predicted and measured net 
radiation, sensible heat, and latent heat are shown in Fig 2 (b) and (c) for typical pre-monsoon (June 13-19, 2012) and monsoon (July 25-31, 2012) seasons. The root mean square errors (RMSE) of $R n, H_{s}$, and $L E_{s}$ are 25, 40, $20 \mathrm{~W} \mathrm{~m}^{-2}$ for the pre-monsoon season and 42, 49, $35 \mathrm{~W}$ $\mathrm{m}^{-2}$ for the monsoon season, respectively. For comparison, it was reported in [36] that the mean RMSE of 31 existing urban energy balance models are 28,66 , and $51 \mathrm{~W} \mathrm{~m}^{-2}$ for $R_{n}, H_{s}$, and $L E_{s}$ respectively, where model performance is generally the best for the net radiation and the worst for the latent heat. The current UCM is of good accuracy especially in terms of the latent heat prediction. Furthermore, the current UCM is applied to estimate surface temperatures for multiple pavements, including asphalt, concrete, and artificial green turf at the CR site in Phoenix (33.44 N, 111.92 W) (sees Fig. 2(d) and Table 1, 2 for more details). The simulated surface temperatures were compared against field measurements using a wireless meteorological network [29] for the period December 23-28, 2012 as shown in Fig. 2(e). The RMSE values for asphalt, concrete and green tur are $0.8,0.8$, and $1.7^{\circ} \mathrm{C}$, respectively.

\subsubsection{Parameterization of tree shading}

Due to the compound shading effects of trees and walls, the radiative exchange inside the street canyon will be difficult to solve using analytical solution [37]. Here, we adopt a stochastic "ray-tracing" method based on Monte Carlo algorithm to capture the radiative exchange processes inside the street canyon with shade trees [30]. For simplicity and without much loss of generality, we make the following assumptions: (1) the total incoming radiation is composed of bundles of rays with random directions and the trajectory of each ray is separately generated and traced, with its emitting directions generated by random numbers; (2) The presentation of tree crowns is simplified using cylindrical geometry with a radius of $R t$, in the $2 \mathrm{D}$ big canyon, as 
shown in Figure 1; and (3) The dimensions of tree trunks are much smaller as compared to tree crowns, and their ray-blocking effect is negligible. Other dimensions for the geometric presentation of trees in the street canyon include the vertical perpendicular distance from tree crown center to the ground $h_{t}$, and the horizontal perpendicular distance from tree crown center to the nearest wall $d_{t}$ (see Fig. 1).

To trace a radiative ray emitted from each canyon facet, the direction of an emitted ray from a surface (surface $i$ ) is determined by the polar angle $\theta_{i}$ and the azimuth angle $\eta_{i}$, which are given by

$$
\begin{gathered}
\theta_{i}=2 \pi R_{\theta} \\
\eta_{i}=\arcsin \left(\sqrt{R_{\eta}}\right)
\end{gathered}
$$

where $R_{\theta}$ and $R_{\eta}$ are independent random numbers. This emitted ray will be traced along a randomly generated direction using Monte Carlo algorithm. If absorbed by a generic surface $j$, it is counted into the view factor $F_{i j}$. Since all reflections between six canyon and tree facets (i.e. sky, ground, two facing walls, and two symmetric tree crowns) are considered, both $i$ and $j$ range from 1 to $6(i \neq j)$. We further assume that all participating facets in the radiative heat exchange are Lambertian and gray, and all radiative reflections (shortwave or longwave) are diffuse in nature. Once the view factors between urban facets are determined, the radiative heat exchange for both shortwave and longwave radiation can be readily obtained $[29,32,38]$.

Physically, with shade trees in the street canyon, the rays emitted from a generic canyon facet (road, walls or the sky) are possibly intercepted by tree crowns, which effectively reduces the view factors between all canyon surfaces (the shading effect). Besides, the location and size of the tree will also influence the view factors. To illustrate, we presented typical view factors from wall to ground (FWG) and wall to wall (FWW) and compare them for different horizontal 
tree locations $d_{t}$, tree trunk heights $h_{t}$, and tree crown sizes $R_{t}$, one in a turn. The canyon dimensions are: wall height $x_{W}=4.5 \mathrm{~m}$, roof width $x_{R}=15 \mathrm{~m}$, and road width $x_{G}=20 \mathrm{~m}$. The results of comparison are shown in Fig. 3. In Fig. 3(a), by keeping tree size as constant $\left(h_{t}=2 \mathrm{~m}\right.$, $R_{t}=2 \mathrm{~m}$ ) and moving the tree horizontally from the wall, i.e. $d_{t}$ ranging from $1 \mathrm{~m}$ to $3 \mathrm{~m}$, FWG increases while FWW remains nearly constant. The reason is when the tree is farther from a wall, fewer rays emitted from the wall are intercepted by trees and more rays will be received by the ground, thus resulting in larger FWG. On the other hand, FWW represents the average view factor seen by the two opposite-faced walls. As the size of the tree does not change ( $h_{t}$ and $R_{t}$ are kept as constant), roughly the same number of rays is exchanged between the two walls, leading to roughly constant FWW.

By keeping tree location and tree crown size as constant $\left(d_{t}=2 \mathrm{~m}, R_{t}=2 \mathrm{~m}\right)$ and changing the tree trunk height $h_{t}$ from $1 \mathrm{~m}$ to $3 \mathrm{~m}$, it is found that both FWG and FWW will decrease first and then increase with the turning point at $2.5 \mathrm{~m}$ (Fig. 3b). This non-monotonic pattern is physical, because when $h_{t}$ is small, the top of the tree crown is lower than the top of the wall (tree crown is completely within the canyon), a taller tree is more effective in shading the canyon. As $h_{t}$ increases beyond the limit where tree crown top levels off with the rooftop (in this case $h_{t}=$ $2.5 \mathrm{~m}$ ), part of the tree crown is outside the canyon and becomes less effective in shading the canyon facet (part of the shade is casted on roof instead of walls or ground), leading to a slight increase in FWG. Lastly, if we keep the tree location and the tree trunk height as constant $\left(h_{t}=2\right.$ $\mathrm{m}, d_{t}=2 \mathrm{~m}$ ) and increase the tree crown radius, both the FWG and FWW will decrease, because more rays will be intercepted by the tree with larger tree crown radius (Fig. 3c). With the presence of trees in the street canyon, the view factors between all canyon facets are reduced and 
the emitted radiative heat received by the canyon facets are decreased, which contributes to the cooling of both walls and ground surfaces.

\subsection{Atmospheric boundary-layer dynamics}

A typical convective $\mathrm{ABL}$ is composed of a surface layer, a mixed layer, and a thin capping inversion layer (i.e. the entrainment zone) [39]. The surface layer conditions, assuming constant fluxes, are parameterized by the UCM. The evolution of temperature and humidity in the mixed layer is governed by the gradient of vertical heat and moisture fluxes along the altitude [40], as

$$
\begin{aligned}
& \frac{\partial \theta_{v}}{\partial t}=\frac{\partial}{\partial z}\left(-\overline{w^{\prime} \theta_{v}^{\prime}}\right) \\
& \frac{\partial q}{\partial t}=\frac{\partial}{\partial z}\left(-\overline{w^{\prime} q^{\prime}}\right)
\end{aligned}
$$

where $\theta_{v}$ is the virtual potential temperature, $q$ is the specific humidity, $w$ is the vertical wind speed, $z$ is the altitude, and $\overline{w^{\prime} \theta_{v}^{\prime}}$ and $\overline{w^{\prime} q^{\prime}}$ are the kinematic eddy heat and moisture fluxes, respectively. The eddy heat and moisture fluxes in the ABL can be parametrized as [41]

$$
\begin{aligned}
-\overline{w^{\prime} \theta_{v}^{\prime}} & =K_{h}\left(\frac{\partial \theta_{v}}{\partial z}-\gamma_{h}\right)-\left(\overline{w^{\prime} \theta_{v}^{\prime}}\right)_{h}\left(\frac{z}{z_{h}}\right)^{3} \\
-\overline{w^{\prime} q^{\prime}} & =K_{h}\left(\frac{\partial q}{\partial z}-\gamma_{q}\right)-\left(\overline{w^{\prime} q^{\prime}}\right)_{h}\left(\frac{z}{z_{h}}\right)^{3}
\end{aligned}
$$

where $K_{h}$ is the turbulent diffusivity, $z_{h}$ and $\gamma_{q}$ are non-local mixing terms of temperature and humidity, $\left(\overline{w^{\prime} \theta_{v}^{\prime}}\right)_{h}$ and $\left(\overline{w^{\prime} q^{\prime}}\right)_{h}$ are the heat and moisture fluxes at the top of the ABL (when $z=$ $Z h), Z_{h}$ is the ABL height, which is determined by an analytical formula proposed by [42] as 


$$
z_{h}=\left\{\begin{array}{l}
z_{h 0}^{2}+\frac{\left(2+4 w_{e}\right)}{\gamma_{\theta v}}\left[\Delta \theta_{v, 0} z_{h 0}^{\frac{1+w_{e}}{w_{e}}}-\left(\frac{w_{e}}{1+2 w_{e}}\right) \gamma_{\theta v} z_{h 0}^{\frac{1+2 w_{e}}{w_{e}}}\right]\left(\hat{z}_{h}^{-\frac{1}{w_{e}}}-z_{h 0}^{-\frac{1}{w_{e}}}\right) \\
+\left(\frac{2+4 w_{e}}{\gamma_{\theta v}}\right)_{t_{0}}^{t}\left(\overline{w^{\prime} \theta_{v}^{\prime}}\right)_{s} d t
\end{array}\right\}^{1 / 2}
$$

where $z_{h 0}$ is the initial $\mathrm{ABL}$ height, $w_{e}$ is the entrainment rate at the inversion, $\gamma_{\theta}$ is the lapse rate in the free atmosphere, $\Delta \theta_{v, 0}$ is the potential temperature difference across the inversion, and $\hat{z}_{h}$ is a correction term. The detailed parameterization process can be found in [19].

The lower boundary condition of the mixed layer is given by the heat and moisture fluxes arising from urban surface, i.e. $\left(\overline{w^{\prime} \theta_{v}^{\prime}}\right)_{s}$ and $\left(\overline{w^{\prime} q^{\prime}}\right)_{s}$ with the subscript $s$ denoting the surface. The surface kinematic eddy fluxes can be converted from surface turbulent fluxes as

$$
\begin{gathered}
\left(\overline{w^{\prime} \theta^{\prime}}\right)_{s}=\frac{H_{s}}{\rho_{a} c_{p}} \\
\left(\overline{w^{\prime} q^{\prime}}\right)_{s}=\frac{L E_{s}}{\rho_{a} L_{v}} \\
\left(\overline{w^{\prime} \theta_{v}^{\prime}}\right)_{s}=0.61 \bar{\theta}\left(\overline{w^{\prime} q^{\prime}}\right)_{s}+(1+0.61 \bar{q})\left(\overline{w^{\prime} \theta^{\prime}}\right)_{s}
\end{gathered}
$$

The upper boundary condition of the $\mathrm{ABL}($ when $z=z h$ ) are then given by

$$
\begin{gathered}
\left(\overline{w^{\prime} \theta_{v}^{\prime}}\right)_{z_{h}}=-0.15\left(\overline{w^{\prime} \theta_{v}^{\prime}}\right)_{s} \\
\left(\overline{w^{\prime} q^{\prime}}\right)_{z_{h}} \approx 0
\end{gathered}
$$

Since the boundary conditions of a convective ABL are controlled by surface fluxes, any modification to the urban surface will lead to the changes of atmospheric dynamics in the ABL.

To evaluate the coupled UCM-SCM framework, we obtained experiment dataset of temperature and humidity profiles at Phoenix site (PHX) from NOAA/ESRL radiosonde 
database (http://esrl.noaa.gov/raobs/) as well as the surface-layer meteorological data from the CR site at Phoenix, AZ [43]. The surface measurements at CR site were preprocessed for despike and gap filling. All atmospheric data in the ESRL Radiosonde database from 1946 to present were subjected to gross error and hydrostatic consistency checks [43]. More experimental information on PHX and CR site can be found in Tables 1 and 2. Comparison of the simulated and observed profiles of virtual potential temperature and specific humidity on July $9^{\text {th }}$, 2013, is shown in Fig. 4. It is clear that the model predictions are in good agreement with the measurement. Note that the coupled modeling framework is completely driven by meteorological variables recorded in the urban surface layer (in this case, by wireless meteorological stations at the CR site $(33.44 \mathrm{~N}, 111.92 \mathrm{~W}))$ nearest to the radiosonde site $(33.45 \mathrm{~N}$, $111.95 \mathrm{~W})$, including solar radiation $\left(S_{d}\right)$, air temperature $\left(T_{a}\right)$, relative humidity $(R H)$, and wind speed (Wsp). The agreement between predicted and measured temperature and humidity profiles

in the ABL not only validates the parameterization of CBL dynamics, but also the accuracy of SLUCM predictions, particularly the total sensible and latent heat arising from the urban area.

\section{Results and Discussion}

In this section, we will use the urban land-atmospheric model (i.e. UCM-SCM) to evaluate the impact of urban vegetation on the urban thermal condition, not only in the surface and near-surface built environment but in the overlying boundary-layer (up to $\sim 2 \mathrm{~km}$ in elevation).

\subsection{Effects of different urban vegetation forms on land surface conditions}


We set the canyon representation for a typical Phoenix residential area with the following dimensions: $x_{W}=4.5 \mathrm{~m}, x_{R}=15 \mathrm{~m}, x_{G}=20 \mathrm{~m}, d_{t}=2 \mathrm{~m}, h_{t}=2 \mathrm{~m}$ (see Fig. 1). Surface atmospheric forcing data of Phoenix from June 13 to June 19, 2012 were collected from EC Tower site to drive the UCM-SCM. The initial surface temperatures for asphalt road and lawn are 45 and $30{ }^{\circ} \mathrm{C}$ respectively. The model also accounts for the difference in water consumption of different vegetation types: irrigation is not applied for xeric trees; whereas for mesic lawns, the initial soil moisture was set as $90 \%$ saturated and the lawn is irrigated at $21 \mathrm{pm}$ (local time) every night in the simulation period to maintain saturated soil moisture in the model so that the cooling efficiency of lawns is not restrained by water availability.

To assess the effect of different urban vegetation forms (mesic grass or xeric tree) on urban land surface conditions, four cases with different combinations of urban vegetation forms were studied including: (1) no grass, no tree (i.e. $f_{g}=0 \%, R_{t}=0 \mathrm{~m}$ ), (2) with grass (irrigated urban lawns), no tree (i.e. $f_{g}=50 \%, R_{t}=0 \mathrm{~m}$ ), (3) no grass, with tree (i.e. $f_{g}=0 \%, R_{t}=1 \mathrm{~m}$ ), (4) with both grass and tree (i.e. $f_{g}=50 \%, R_{t}=1 \mathrm{~m}$ ). Note that per the parameterization schemes of the UCM (Section 2.1), irrigated urban lawns (grass) here represents the mesic urban landscape, while shade trees represent the xeric landscape where little (or no) irrigation is needed and the latent heat associated with ET is negligible.

Since thermal stress is more severe during daytime than nighttime in the study area, we show here a weekly averaged daytime ground surface temperatures $\left(T_{G}\right)$, canyon air temperatures ( $\left.T_{c a n}\right)$, and canyon air humidity $\left(q_{c a n}\right)$ from 9 am to $18 \mathrm{pm}$ in Fig. 5 . The completely de-vegetated case (Case 1), as expected, yields the highest canyon air temperature, and lowest humidity (completely dry), while the most vegetated case (Case 4) with both types of vegetation has the lowest ground temperature, lowest canyon air temperature and highest humidity. This is expected 
and demonstrates that urban vegetation, either mesic or xeric, is effective to mitigate excessive heating in the city. The cases with only one type of vegetation (Case 2 and Case 3) have similar effects on reducing ground temperature and canyon air temperature. Case 2 (with grass only) has lower surface temperature but higher canyon air temperature than Case 3 (with trees only). This is because urban lawns and shade trees have different cooling mechanisms: well-irrigated grass cools the surface and canyon air by reducing surface sensible heat fluxes and increasing surface latent heat fluxes. Shade trees, on the other hand, reduce the urban thermal stress via radiative shading. Note that trees shade not only ground but also walls, leading to less building energy load and waste heat dumped to the street canyon. In addition, the mesic urban landscape (Case 2) yields higher humidity in the canyon via ET, than that of the xeric landscape (Case 3).

In addition, in hot summers of arid regions, urban residents experience thermal discomfort due to intensive solar radiation, high outdoor air temperature, and low relative humidity. There are many different ways for measuring the thermal stress and human comfort conditions in urban areas, by accounting environmental (meteorological), biological, and socio-economic factors [44]. Some widely used indices to quantify thermal comfort include the predicted mean vote index (PMV), the physiological equivalent temperature (PET), etc. [45]. The thermal comfort assessments are usually made by accounting for pedestrian's thermal tolerance and skin temperature. One practical concern of using indices like PMV or PET is that they require subjective data collection such as human body temperatures based on large population.

For simplicity, here we adopt a simple temperature-humidity index (THI) [16], given by

$$
\mathrm{THI}=T_{a}-0.55\left(1-\frac{R H}{100}\right)\left(T_{a}-14.44\right)
$$

where $T_{a}$ is the air temperature $\left({ }^{\circ} \mathrm{C}\right), R H$ is the relative humidity $(\%)$. Reducing THI improves the thermal comfortableness for pedestrians. Note that when THI is higher than $27^{\circ} \mathrm{C}$, people will 
experience heat fatigue and health risks. Comparison of the THI for the four cases is shown in Fig. 5(d), the index exceeds $27^{\circ} \mathrm{C}$ around noon in the de-vegetated case, while the THI is less than $27^{\circ} \mathrm{C}$ for all vegetated cases despite the vegetation type. The mesic landscape improves the outdoor thermal comfort (smaller THI) by reducing air temperature and increasing air humidity through ET; while the xeric landscape enhances thermal comfort by not only shading the urban land surface, but also directly shading the pedestrians on the street. The direct shading effect on pedestrians, measured by the contrast between the shaded and radiant temperatures as experienced by pedestrians for instance, is not considered here.

\subsection{Effects of different urban vegetation forms on the ABL dynamics}

The urban landscape modification and land use land cover changes will influence the surface energy and water transport processes, and further alter local hydroclimate due to urban land-atmospheric interactions [19]. As the lower boundary of the ABL, any changes in the land surface states will eventually be manifest in the boundary-layer structure and dynamics. A better understanding on the impacts of urban vegetation on the ABL is essential to assess urban vulnerability to climate change [46].

In Fig. 6, three dynamical indicators of the daytime ABL, i.e. the ABL height, the mean virtual potential temperature, and the mean specific humidity in the convective mixed layer were compared for the aforementioned cases in section 3.1. An urban area without presence of vegetation (a "desert" city, Case 1) exhibits the highest temperature and highest ABL height, consistent to the general boundary-layer theory. Also, both mesic (with irrigated lawns of 50\% ground surface coverage, Case 2) and xeric (with shade trees of $1 \mathrm{~m}$ radius, Case 3) can effectively lower the mean temperature in the mixed layer. This demonstrates that the cooling 
effect of urban vegetation is not only capable of reducing temperatures of canyon facets (associated with the so-called surface urban heat island or SUHI effect), or canyon air (associated with the conventional UHI effect), as shown in Fig. 5, but can penetrate into the convective (daytime) boundary layer overlying the built terrain. Also note that with presence of both mesic and xeric landscapes (Case 4), further cooling of ABL is marginal. As ABL height is primarily dominated by the amount of sensible heat transported from the urban surface layer, which is in turn governed by the surface and canyon temperatures, the evolution of ABL height follows very similar trend to that of the mixed-layer temperature (Fig. 6 (a)\&(b)).

As the humidity in the ABL is concerned, we found it is intriguing that the presence of shade trees in urban areas seems to impede the ET process, hence leading to lower humidity level in the mixed-layer (Fig. 6c). This is not non-physical, as shade trees alter the surface energy

balance by reducing the amount of available energy (solar radiation) incident on canyon surfaces, which resulted in a simultaneous reduction of turbulent fluxes (sensible and latent heat). Owing to the simplification of tree representation in the street canyon that they do not participate in the exchange of thermal radiative energy with walls and ground surfaces, the blockage of radiation by tree shading is likely to be over-estimated. Further improvement of the UCM is needed for capturing surface energy partitioning inside the street canyon with better numerical accuracy.

\subsection{Relative impact of mesic and xeric landscapes}

To better assess the impacts of different vegetation types on local outdoor microclimate, we applied the urban land-atmospheric framework to simulate more landscaping scenarios (viz. 30 different combination of grass fraction and tree crown radius) as described in Table 3 . The grass fraction varies from 0 to $50 \%$ with the interval of $5 \%$. The tree crown radius varies from 0 to $2 \mathrm{~m}$ 
with the interval of $0.5 \mathrm{~m}$. The urban surface condition and ABL dynamics of each landscaping scenario were presented and compared in Table 3.

In the urban surface layer, increasing grass fraction or tree sizes cools the canyon air, as presented in Fig. 7(a). When tree crown radius is small, the temperature decreases and moisture increases by grass are more significant. When tree crown radius is large, the cooling effects of grass will be restrained. From Table 4, the canyon air temperature difference between $50 \%$ grass and $0 \%$ grass for various tree crown radiuses, i.e. $0 \mathrm{~m}, 0.5 \mathrm{~m}, 1 \mathrm{~m}, 1.5 \mathrm{~m}$, and $2 \mathrm{~m}$ are $-5.0{ }^{\circ} \mathrm{C},-4.3$ ${ }^{\circ} \mathrm{C},-3.3{ }^{\circ} \mathrm{C},-2.9^{\circ} \mathrm{C}$, and $-2.5^{\circ} \mathrm{C}$ respectively. Since the moisture source of canyon air is mainly from grasses, the canyon air humidity will increase with grass fraction. For less grass fraction (when $f_{g}<5 \%$ ) and larger tree crown (when $r_{t}>1 \mathrm{~m}$ ), the air humidity will not change as in Fig. 7(b). The canyon air humidity difference between $50 \%$ grass and $0 \%$ grass for different tree crown radii, i.e. $0,0.5,1,1.5$, and $2 \mathrm{~m}$ are $12.3,16.1,23.1,23.2,23.8 \mathrm{~kg} \mathrm{~kg}^{-1}$, respectively as listed in Table 4. The cooling efficiency and evaporative efficiency of grass are restrained by large tree crown, since the turbulence dissipation on the ground surface has been restrained by lower surface temperature and the Bowen ratio $\left(H_{s} / L E_{s}\right)$ will be larger with smaller surface temperature [47]. The change of turbulent sensible and latent heat fluxes from $0 \%$ grass to $50 \%$ grass will be smaller with larger tree crown.

For the overlying atmosphere, the increase of grass fraction or tree size reduces ABL height and virtual potential temperature in the mixed layer. When tree crown radius is large enough $\left(R_{t}>1 \mathrm{~m}\right)$, both the ABL height and the mean temperature in the mixed layer will not be changed with further increasing tree crown radius or increasing grass fraction. This is because of the constraint (lower bound) of the surface sensible heat dissipation efficiency has been reached under significant shading effect. On the other hand, since grass is assumed as the only moisture 
source, the mean specific humidity in the mixed layer will increase with more grass fraction as in Fig. 8(c). Since shade tree will reduce the surface temperature and latent heat flux generation efficiency, the humidity change in the mixed layer will be more significant for smaller trees.

\section{Concluding remarks}

In this study, a coupled urban land-atmosphere framework was used to model the impact of different urban vegetation on local microclimate, not only within the canopy layer, but extended to the overlying convective boundary layer. It is found that both mesic and xeric vegetation can improve the outdoor thermal environment, via different cooling mechanisms. In a desert city like Phoenix, xeric tree may be preferred to mesic urban lawns for daytime cooling due to: (1) xeric tree can cool the city with less water consumption than lawns; and (2) the cooling efficiency of lawns is constrained by cool surface shaded by xeric trees. In addition to heat stress mitigation, extra humidity evapotranspirated from mesic vegetation also plays an important role in determining the outdoor thermal comfort. Furthermore, urban vegetation effectively alters the surface energy partitioning, which in turn modifies the overlying atmospheric dynamics (ABL height, thermal structure, and abundance of humidity). The ABL height as well as mean temperature and humidity in the ABL are very sensitive to the presence of urban vegetation. The modification of ABL dynamics has profound implications to the local hydroclimate via landatmosphere interactions, especially under the regional climate changes. 


\section{Acknowledgements}

This work is supported by the US National Science Foundation (NSF) under grant number CBET-1435881. The authors thank the NOAA/ESRL/Global Systems Division for providing the sounding data at the Phoenix site. Field measurement of the eddy covariance tower at Maryvale, West Phoenix sponsored by NSF under grant EF-1049251 is also acknowledged. 


\section{References}

[1] Chow WTL, Brazel AJ. Assessing xeriscaping as a sustainable heat island mitigation approach for a desert city. Build Environ. 2012;47:170-81.

[2] McPherson EG. Urban forestry in North America. Renew Res J. 2006;24:8.

[3] Price C. Quantifying the aesthetic benefits of urban forestry. Urban Forestry Urban Greening. 2003;1:123-33.

[4] Sun T, Bou-Zeid E, Wang ZH, Zerba E, Ni GH. Hydrological determinants of green roof performance via a vertically-resolved model for heat and water transport. Build Environ. $2013 ; 60: 211-24$.

[5] Yang J, Wang ZH. Physical parameterization and sensitivity of urban hydrological models: Application to green roof systems. Build Environ. 2014;75:250-63.

[6] Yang J, Wang ZH, Chen F, Miao S, Tewari M, Voogt J, et al. Enhancing hydrologic modeling in the coupled Weather Research and Forecasting - urban modeling system. Boundary-Layer Meteorol. 2015;155:87-109.

[7] Sadler J, Bates A, Hale J, James P. Bringing cities alive: the importance of urban green spaces for people and biodiversity. In: Gaston, K.J., editor. Urban Ecology, Cambridge University Press, Cambridge. 2010:230-60.

[8] Smardon RC. Perception and aesthetics of the urban environment: Review of the role of vegetation. Landscape Urban Plan. 1988;15:85-106.

[9] Takebayashi H, Moriyama M. Surface heat budget on green roof and high reflection roof for mitigation of urban heat island. Build Environ. 2007;42:2971-9. 
[10] Park M, Hagishima A, Tanimoto J, Narita KI. Effect of urban vegetation on outdoor thermal environment: Field measurement at a scale model site. Build Environ. 2012;56:3846.

[11] Hedquist BC, Brazel A. Seasonal variability of temperatures and outdoor human comfort in Phoenix, Arizona, U.S.A. Build Environ. 2014;72:377-388.

[12] Gober P, Brazel A, Quay R, Myint S, Grossman-Clarke S, Miller A, et al. Using watered landscapes to manipulate urban heat island effects: how much water will it take to cool Phoenix? J Amer Plan Assoc. 2009;76:109-21.

[13] Guhathakurta S, Gober P. The impact of the Phoenix urban heat island on residential water use. J Amer Plan Assoc. 2007;73:317-29.

[14] Martin CA, Stabler LB. Plant gas exchange and water status in urban desert landscapes. J Arid Environ. 2002;51:235-54.

[15] Martinelli L, Lin TP, Matzarakis A. Assessment of the influence of daily shadings pattern on human thermal comfort and attendance in Rome during summer period. Build Environ. 2015;92:30-38.

[16] Abdel-Ghany A, Al-Helal I, Shady M. Human thermal comfort and heat stress in an outdoor urban arid environment: a case study. Adv Meteorol. 2013;2013:1-7.

[17] Shashua-Bar L, Pearlmutter D, Erell E. The influence of trees and grass on outdoor thermal comfort in a hot-arid environment. Int J Climatol. 2011;31:1498-506.

[18] Volo TJ, Vivoni ER, Martin CA, Earl S, Ruddell BL. Modelling soil moisture, water partitioning, and plant water stress under irrigated conditions in desert urban areas. Ecohydrol. 2014;7:1297-313. 
[19] Song J, Wang Z-H. Interfacing the Urban Land-Atmosphere System Through Coupled Urban Canopy and Atmospheric Models. Boundary -Layer Meteorol. 2015;154:427-48.

[20] Song J, Wang Z-H, Myint SW, Wang C, Little D. Statistical analysis of local urban climatology of Phoenix Metropolitan area, Arizona. Urban Clim. 2015; under rview.

[21] Brazel A, Selover N, Vose R, Heisler G. The tale of two climates-Baltimore and Phoenix urban LTER sites. Clim Res. 2000;15:123-35.

[22] Balling RC, Gober P. Climate variability and residential water use in the city of Phoenix, Arizona. J Appl Meteorol Clim. 2007;46:1130-7.

[23] Balling RC, Gober P, Jones N. Sensitivity of residential water consumption to variations in climate: an intraurban analysis of Phoenix, Arizona. Water Resour Res. 2008;44:W10401.

[24] Phoenix Co. Water resources plan: 2005 update. Phoenix, AZ: City of Phoenix Water Services Department. 2005.

[25] Armson D, Stringer P, Ennos AR. The effect of tree shade and grass on surface and globe temperatures in an urban area. Urban Forestry Urban Greening. 2012;11:245-255.

[26] Middel A, Hab K, Brazel AJ, Martin CA, Guhathakurta S. Impact of urban form and design on mid-afternoon microclimate in Phoenix local climate zones. Landscape Urban Plan. 2014;122:16-28.

[27] Ali-Toudert F, Mayer H. Thermal comfort in an east-west oriented street canyon in Freiburg (Germany) under hot summer conditions. Theor Appl Climatol. 2007;87: 223-237.

[28] Johansson E, Emmanuel R. The influence of urban design on outdoor thermal comfort in the hot, humid city of Colombo, Sri Lanka. Int J Biometeorol. 2006;51:119-133. 
[29] Wang ZH, Bou-Zeid E, Smith JA. A coupled energy transport and hydrological model for urban canopies evaluated using a wireless sensor network. Q J R Meteorol Soc. 2013;139:1643-57.

[30] Wang Z-H. Monte Carlo simulations of radiative heat exchange in a street canyon with trees. Sol Energy. 2014;110:704-13.

[31] Arnfield AJ. Two decades of urban climate research: a review of turbulence, exchanges of energy and water, and the urban heat island. Int J Climatol. 2003;23:1-26.

[32] Masson V. A Physically-Based Scheme For The Urban Energy Budget In Atmospheric Models. Boundary-Layer Meteorol. 2000;94:357-97.

[33] Wang ZH, Bou-Zeid E, Smith JA. A spatially-analytical scheme for surface temperatures and conductive heat fluxes in urban canopy models. Bound-Layer Meteor. 2011;138:17193.

[34] Brutsaert W, Knovel. Hydrology: An introduction. Cambridge: Cambridge University Press; 2005.

[35] Chow WT, Volo YJ, Vivoni ER, Jenerette GD, Ruddell BL. Seasonal dynamics of a suburban energy balance in Phoenix, Arizona. Int J Climatol. 2014;34:3863-80.

[36] Grimmond CSB, Blackett M, Best MJ, Baik JJ, Belcher SE, Beringer J, et al. Initial results from Phase 2 of the international urban energy balance model comparison. Int J Climatol. 2011;31:244-72.

[37] Krayenhoff E, Christen A, Martilli A, Oke T. A multi-layer radiation model for urban neighbourhoods with trees. Boundary-Layer Meteorol. 2014;151:139-78. 
[38] Kusaka H, Kondo H, Kikegawa Y, Kimura F. A Simple Single-Layer Urban Canopy Model For Atmospheric Models: Comparison With Multi-Layer And Slab Models. BoundaryLayer Meteorol. 2001;101:329-58.

[39] Stull RB. An introduction to boundary layer meteorology. Dordrecht: Kluwer Academic Publishers; 1988.

[40] Troen I, Mahrt L. A simple model of the atmospheric boundary layer; sensitivity to surface evaporation. Boundary-Layer Meteorol. 1986;37:129-48.

[41] Noh Y, Cheon WG, Hong SY, Raasch S. Improvement of the K-profile Model for the Planetary Boundary Layer based on Large Eddy Simulation Data. Boundary-Layer Meteorol. 2003;107:401-27.

[42] Ouwersloot HG, Vilà-Guerau de Arellano J. Analytical Solution for the ConvectivelyMixed Atmospheric Boundary Layer. Boundary-Layer Meteorol. 2013;148:557-83.

[43] Schwartz BE and Govett M. A hydrostatically consistent North American radiosonde data base at the forecast systems laboratory, 1946-present. NOAA Technical Memorandum ERL FSL-4, 1992.

[44] Mishra AK, Ramgopal M. Field studies on human thermal comfort-an overview. Build Environ. 2013;64:94-106.

[45] Chen L, Ng E. Outdoor thermal comfort and outdoor activities: A review of research in the past decade. Cities. 2012;29:118-125.

[46] Masson V, Marchadier C, Adolphe L, Aguejdad R, Avner P, Bonhomme M, et al. Adapting cities to climate change: A systemic modelling approach. Urban Clim. 2014;10:407-29.

[47] Yang J, Wang ZH. Land surface energy partitioning revisited: A novel approach based on single depth soil measurement. Geophys Res Lett. 2014;41:8348-58. 
[48] Toparlar Y, Blocken B, Vos P, van Heijst GJF, Janssen WD, van Hooff T, et al. CFD simulation and validation of urban microclimate: A case study for Bergpolder Zuid, Rotterdam. Build Environ. 2015;83:79-90.

[49] Gromke C, Blocken B, Janssen W, Merema B, van Hooff T, Timmermans H. CFD analysis of transpirational cooling by vegetation: Case study for specific meteorological conditions during a heat wave in Arnhem, Netherlands. Build Environ. 2015;83:11-26.

[50] Ramponi R, Blocken B, de Coo LB, Janssen WD. CFD simulation of outdoor ventilation of generic urban configurations with different urban densities and equal and unequal street widths. Build Environ. 2015;92:152-66.

[51] Middel A, Hab K, Brazel AJ, Martin CA, Guhathakurta S. Impact of urban form and design on mid-afternoon microclimate in Phoenix Local Climate Zones. Landscape Urban Plan. 2014;122:16-28. 


\section{Captions of figures}

Fig. 1 Schematic of urban land configuration and processes represented by a two-dimensional big canyon: xeric and mesic landscapes are represented by irrigated lawns and shade trees respectively.

Fig. 2 (a) The eddy covariance tower at Maryvale, west Phoenix, and sample comparison of energy fluxes from UCM predictions and field measurements by the EC tower for (b) the premonsoon (June 13-19, 2012) and (c) the monsoon (July 25-31, 2012) seasons; And (d) field measurement over different pavement types, viz. asphalt, concrete, and artificial green turf, and (e) comparison of measured and model predicted pavement surface temperatures, at the CR site.

Fig. 3 Variations of view factors (FWG and FWW) for different (a) tree location $d_{t}$, (b) tree trunk height $h_{t}$, and (c) tree crown radius $R_{t}$.

Fig. 4 Comparison of the predicted and measured vertical distribution of (a) virtual potential temperature and (b) specific humidity at $16: 37$ pm (LST) on July $9^{\text {th }}, 2013$, at the NOAA ERSL radiosonde Phoenix site.

Fig. 5 Diurnal evolution of (a) ground temperature $T_{G}$, (b) canyon air temperature $T_{\text {can, }}$ (c) canyon air humidity $q_{c a n}$, and (d) thermal comfort index THI from 9 am to 18 pm, averaged from June 13 to June 19, 2012.

Fig. 6 Evolution of (a) ABL height $z_{h}$, (b) the mean virtual potential temperature $\theta_{v}$, and (c) specific humidity $q$ of the mixed layer from 9 am to 18 pm, averaged from June 13 to June 19 , 2012.

Fig. 7 Contour plots of (a) maximum canyon air temperature, $T_{c a n}(\mathrm{~K})$ and (b) maximum canyon air humidity, $q_{\text {can }}\left(\times 10^{-3} \mathrm{~kg} \mathrm{~kg}^{-1}\right)$ for different combinations of grass fraction and tree crown radius. 
Fig. 8 Contour plots of (a) maximum ABL height, $z_{h}(\mathrm{~m})$, (b) maximum virtual potential temperature, $\theta_{v}(\mathrm{~K})$, and (c) maximum specific humidity, $q\left(\times 10^{-3} \mathrm{~kg} \mathrm{~kg}^{-1}\right)$ for different combinations of grass fraction and tree crown radius. 


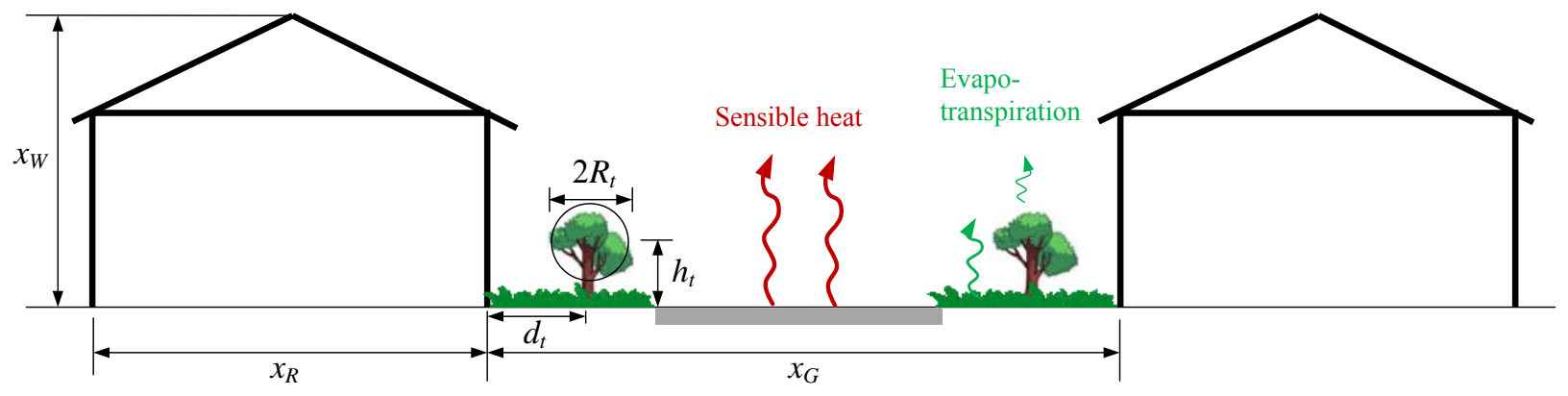

Fig. 1 Schematic of urban land configuration and processes represented by a two-dimensional big canyon: xeric and mesic landscapes are represented by irrigated lawns and shade trees respectively. 
(a)

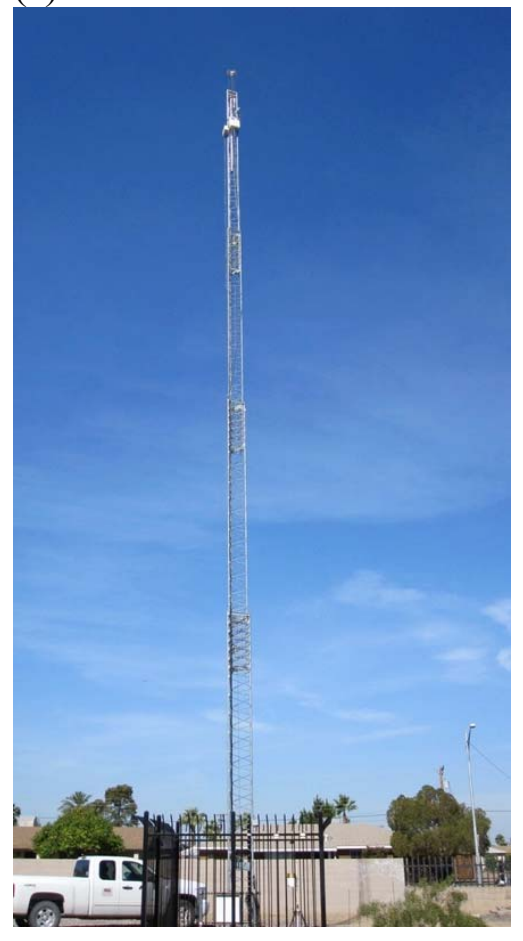

(d)

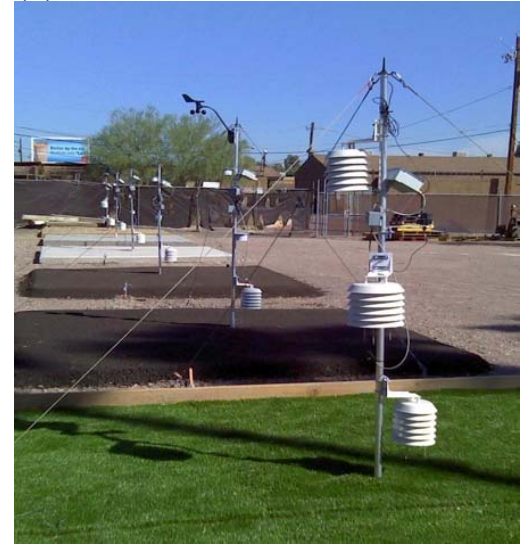

(b)

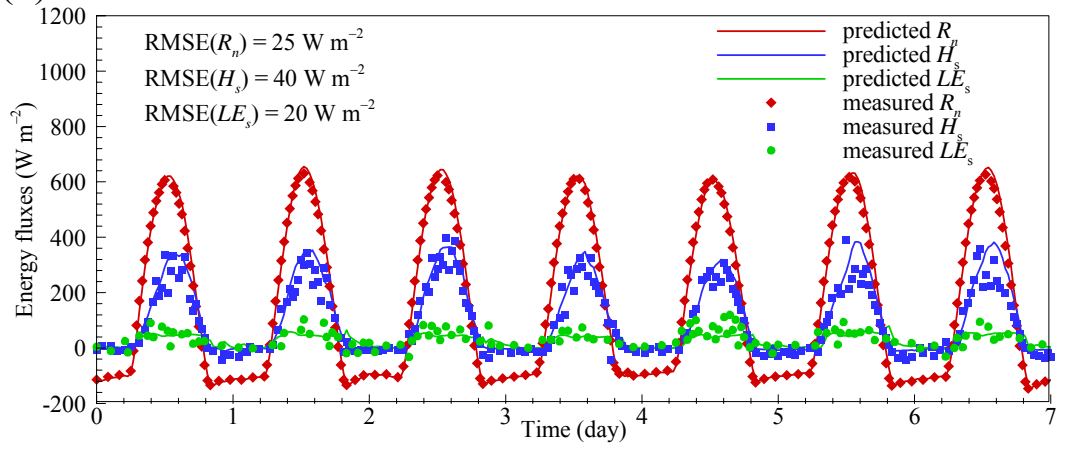

(c)

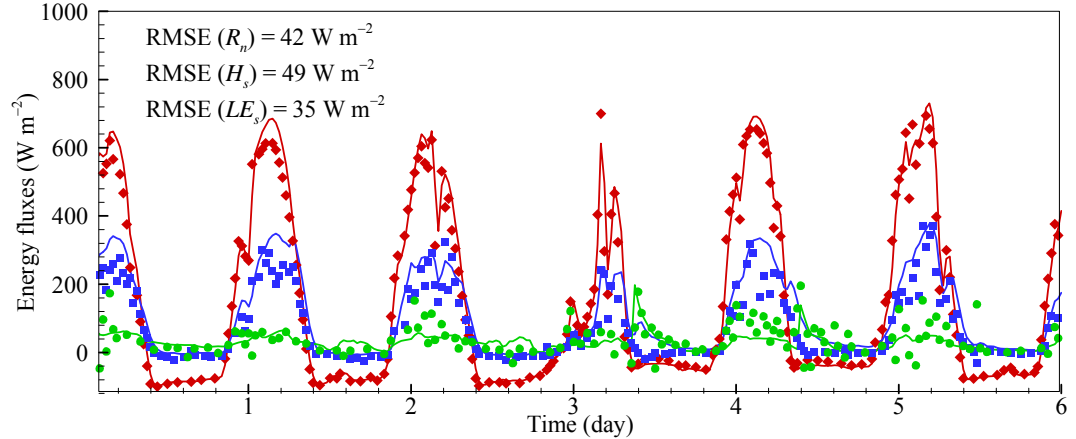

(e)

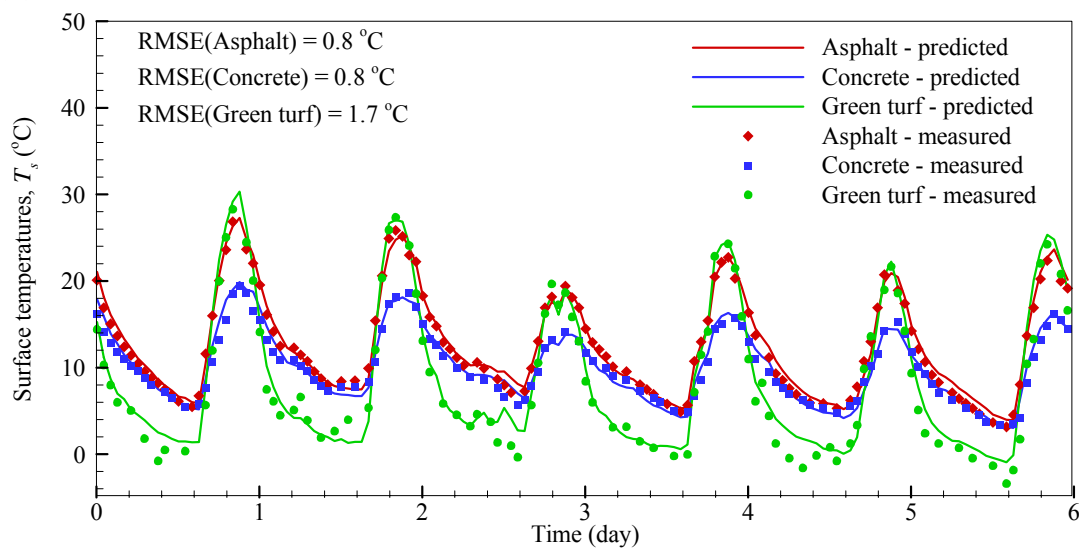

Fig. 2 (a) The eddy covariance tower at Maryvale, west Phoenix, and sample comparison of energy fluxes from UCM predictions and field measurements by the EC tower for (b) the premonsoon (June 13-19, 2012) and (c) the monsoon (July 25-31, 2012) seasons; And (d) field measurement over different pavement types, viz. asphalt, concrete, and artificial green turf, and (e) comparison of measured and model predicted pavement surface temperatures, at the CR site. 
(a)

(b)

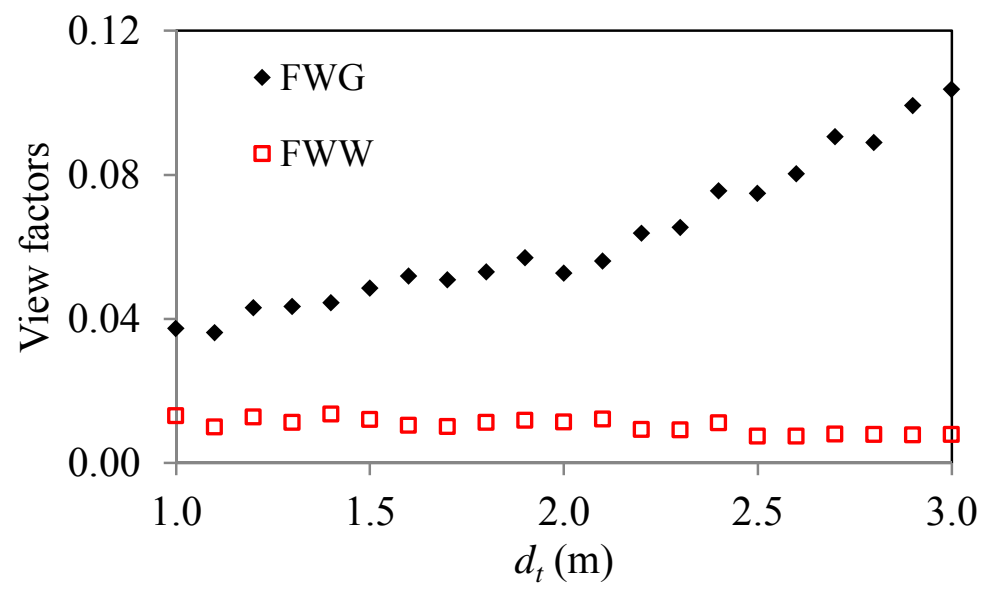

(c)
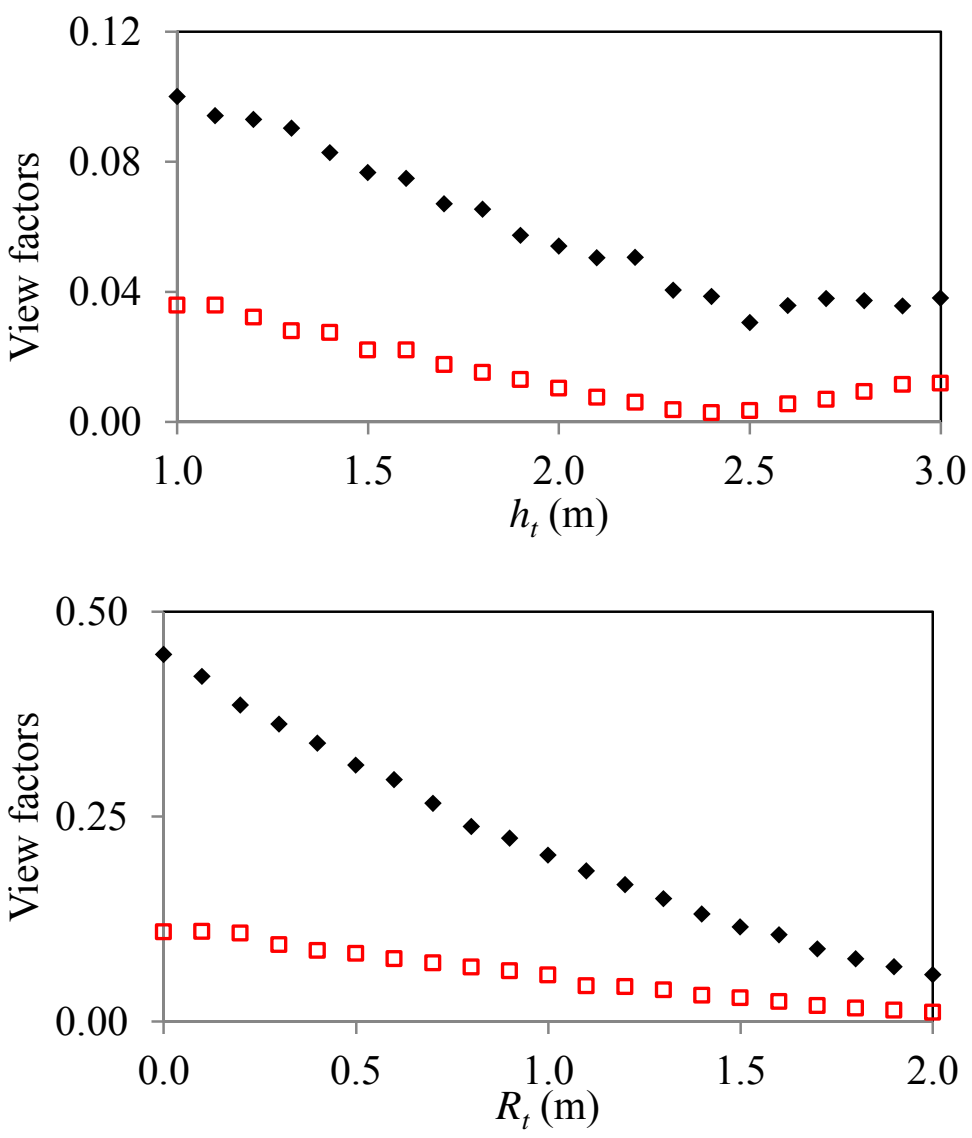

Fig. 3 Variations of view factors (FWG and FWW) for different (a) tree location $d_{t}$, (b) tree trunk height $h_{t}$, and (c) tree crown radius $R_{t}$. 
(a)

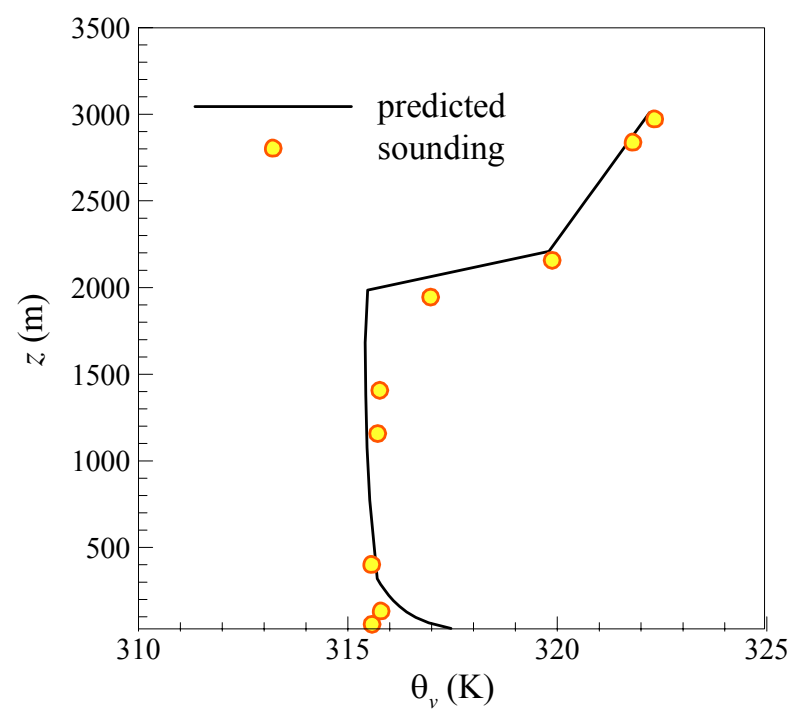

(b)

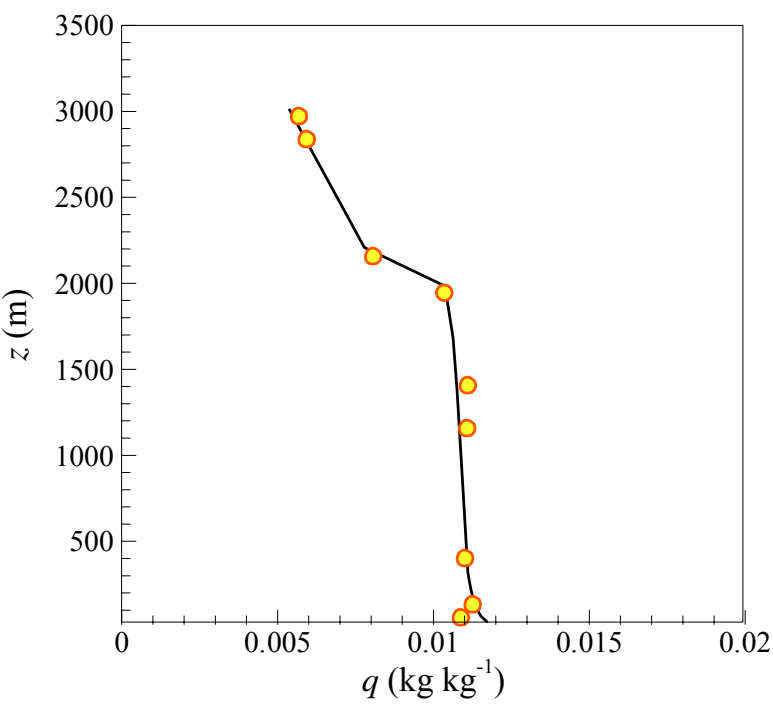

Fig. 4 Comparison of the predicted and measured vertical distribution of (a) virtual potential temperature and (b) specific humidity at 16:37 pm (LST) on July $9^{\text {th }}, 2013$, at the NOAA ERSL radiosonde Phoenix site. 
(a)

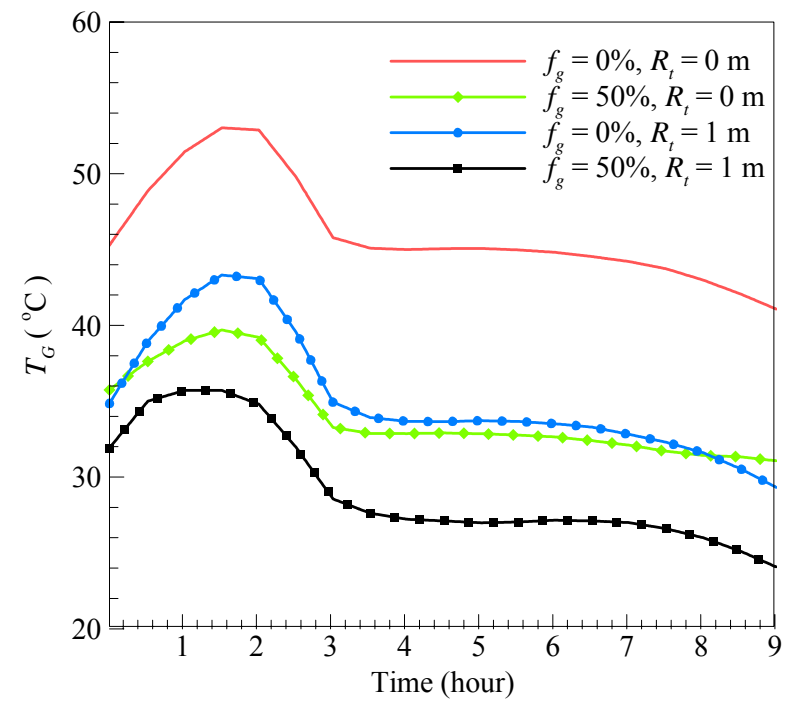

(c)

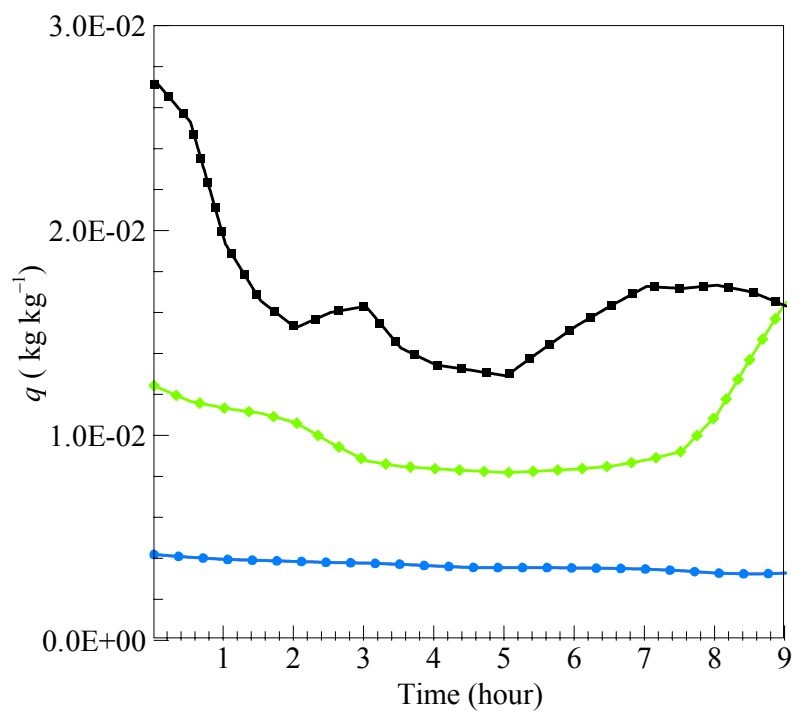

(b)

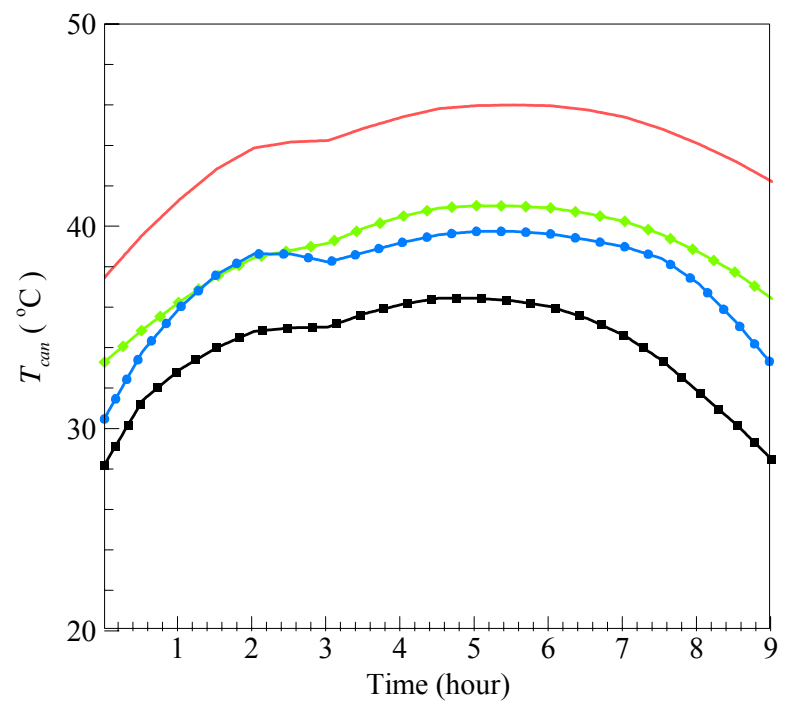

(d)

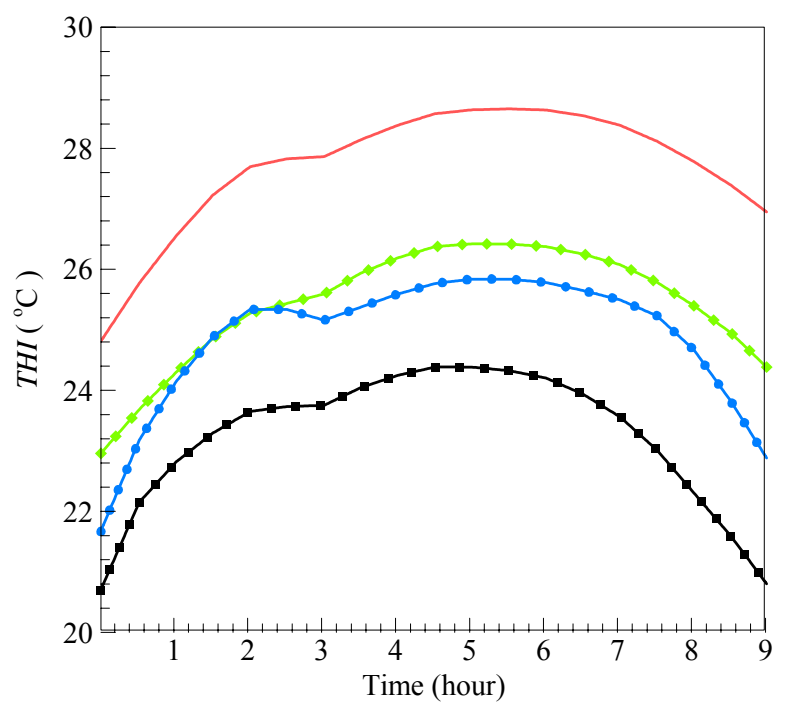

Fig. 5 Diurnal evolution of (a) ground temperature $T_{G}$, (b) canyon air temperature $T_{c a n}$, (c) canyon air humidity $q_{c a n}$, and (d) thermal comfort index THI from 9 am to $18 \mathrm{pm}$, averaged from June 13 to June 19, 2012. 
(a)

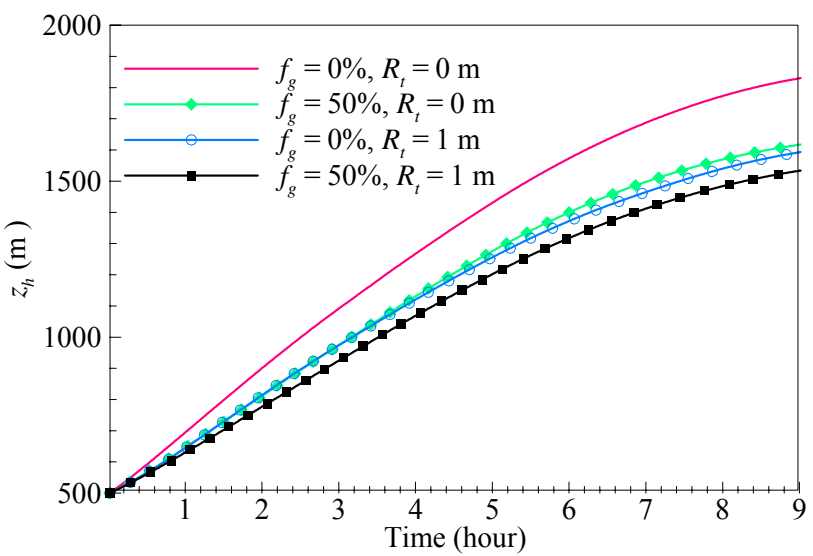

(b)

(c)
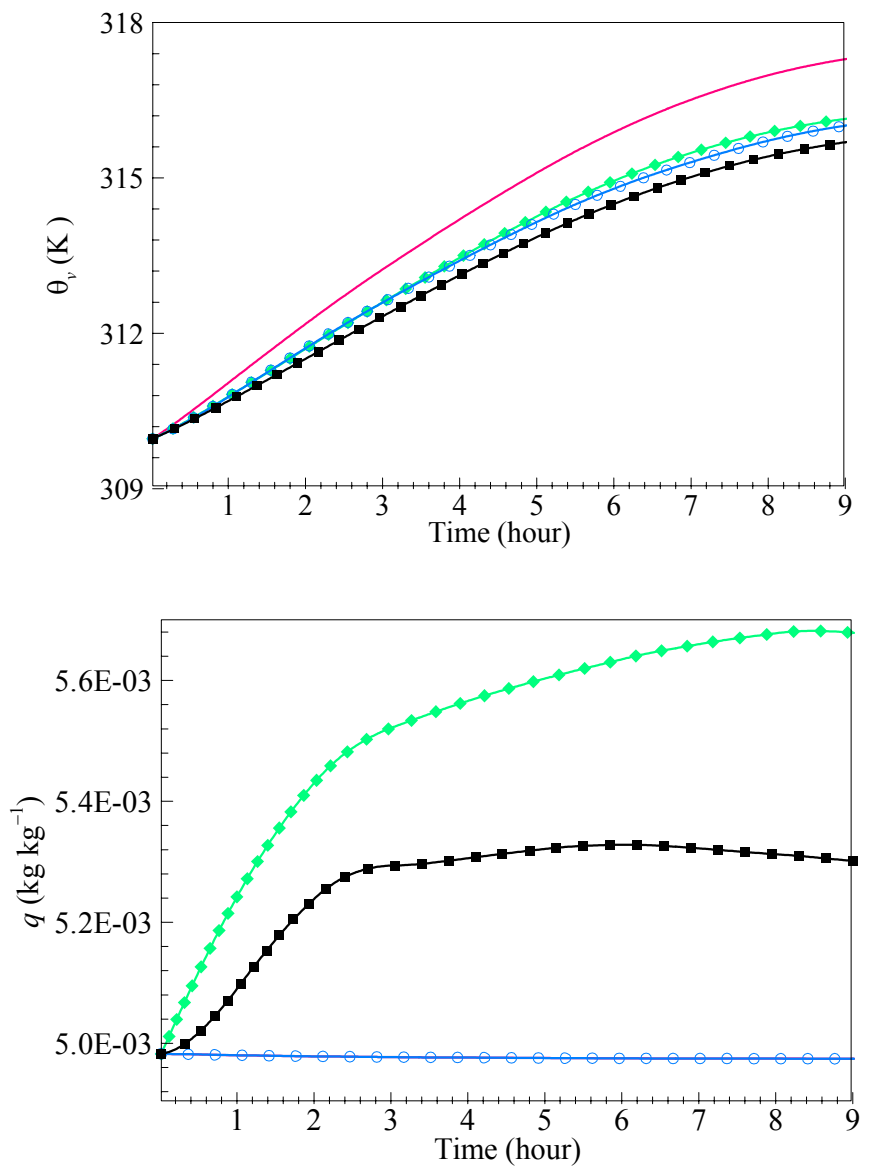

Fig. 6 Evolution of (a) ABL height $z h$, (b) the mean virtual potential temperature $\theta_{v}$, and (c) specific humidity $q$ of the mixed layer from 9 am to 18 pm, averaged from June 13 to June 19, 2012. 
(a)

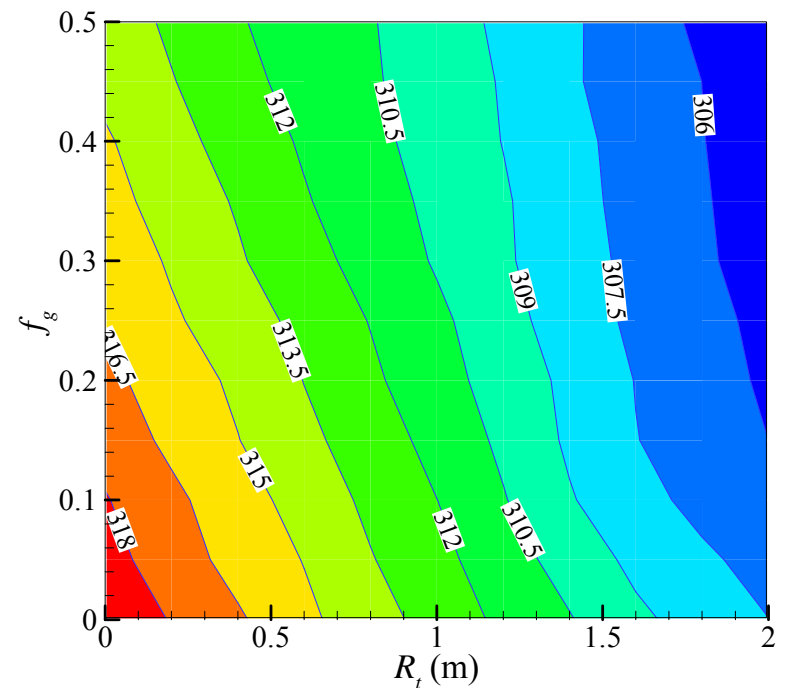

(b)

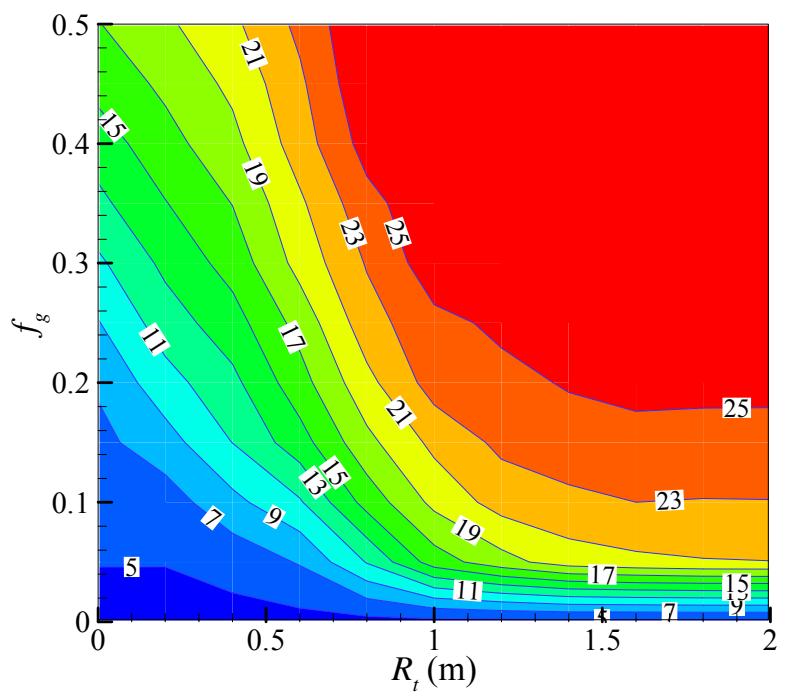

Fig. 7 Contour plots of (a) maximum canyon air temperature, $T_{c a n}(\mathrm{~K})$ and (b) maximum canyon air humidity, $q_{\text {can }}\left(\times 10^{-3} \mathrm{~kg} \mathrm{~kg}^{-1}\right)$ for different combinations of grass fraction and tree crown radius. 
(a)

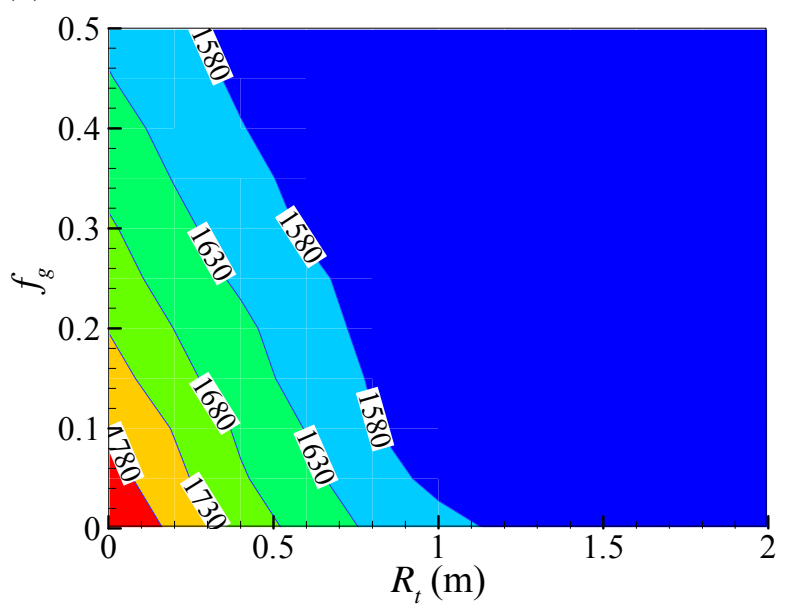

(c)

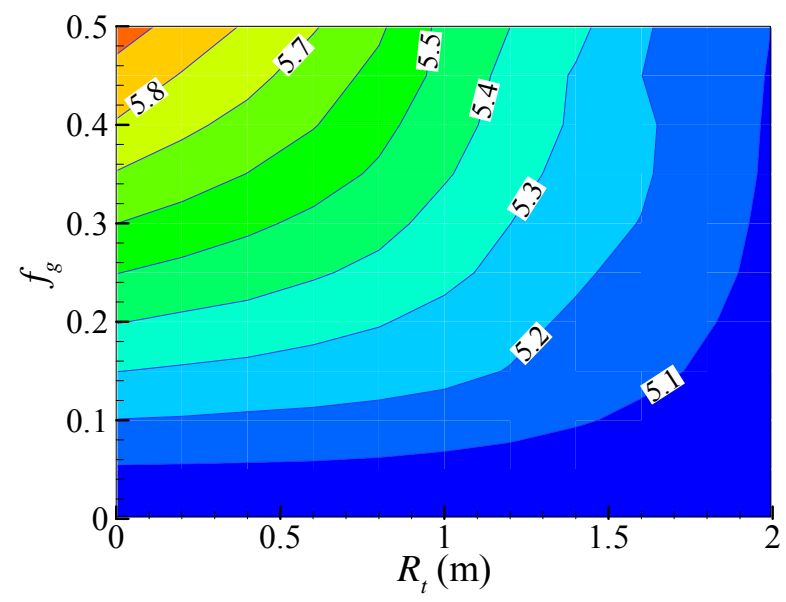

(b)

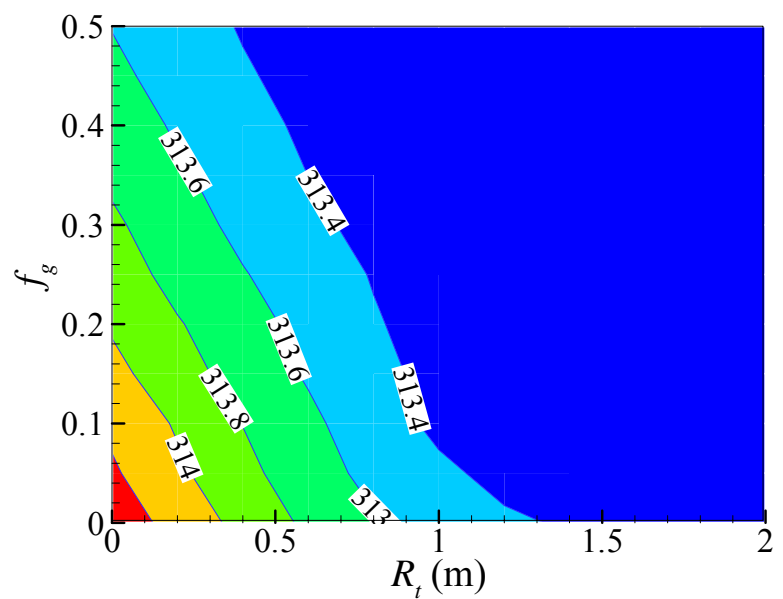

Fig. 8 Contour plots of (a) maximum ABL height, $z_{h}(m)$, (b) maximum virtual potential temperature, $\theta_{v}(\mathrm{~K})$, and (c) maximum specific humidity, $q\left(\times 10^{-3} \mathrm{~kg} \mathrm{~kg}^{-1}\right)$ for different combinations of grass fraction and tree crown radius. 
Table 1. Description of the experiment sites

\begin{tabular}{|c|c|c|c|c|c|}
\hline Site name & $\begin{array}{c}\text { Installation } \\
\text { Date }\end{array}$ & Period & $\begin{array}{c}\text { Site } \\
\text { description }\end{array}$ & Site location & $\begin{array}{l}\text { Measurements } \\
\text { used in this study }\end{array}$ \\
\hline $\begin{array}{c}\text { EC } \\
\text { Tower }\end{array}$ & $\begin{array}{l}\text { November } \\
2011\end{array}$ & $\begin{array}{c}\text { June } 13-19, \\
2012 ; \\
\text { July } 25-31, \\
2012\end{array}$ & $\begin{array}{c}\text { CAP LTER } \\
\text { flux tower } \\
{[35]}\end{array}$ & $\begin{array}{c}(33.48 \mathrm{~N}, 112.14 \\
\mathrm{W})\end{array}$ & $R_{n}, H_{s}, L E_{s}$ \\
\hline $\begin{array}{c}\text { CR } \\
\text { Pavement }\end{array}$ & August 2012 & $\begin{array}{c}\text { December } 23- \\
28,2012\end{array}$ & $\begin{array}{c}\text { Network of } \\
\text { wireless } \\
\text { meteorologica } \\
\text { 1 stations [29] }\end{array}$ & $\begin{array}{c}(33.44 \mathrm{~N}, 111.92 \\
\mathrm{W})\end{array}$ & $S_{d}, T_{a}, T_{s}, R H, W_{s p}$ \\
\hline $\begin{array}{c}\text { ESRL/PH } \\
\mathrm{X}\end{array}$ & 1946 & $\begin{array}{c}\text { July } 2, \text { July } 9, \\
2013\end{array}$ & $\begin{array}{l}\text { NOAA/ESRL } \\
\text { radiosonde } \\
\text { station [43] }\end{array}$ & $\begin{array}{c}(33.45 \mathrm{~N}, 111.95 \\
\mathrm{W})\end{array}$ & $\theta_{v}, q$ \\
\hline
\end{tabular}


Table 2. Instrumentation at experimental sites

\begin{tabular}{|c|c|c|c|}
\hline Site & Sensors & Manufacturer/model & Variable measured \\
\hline \multirow{4}{*}{ EC Tower } & 3D sonic anemometer & $\begin{array}{c}\text { Campbell } \\
\text { Scientific/CSAT3 }\end{array}$ & $\begin{array}{l}\text { Three-dimensional } \\
\text { wind velocities, virtual } \\
\text { sonic temperature }\end{array}$ \\
\hline & Infrared gas analyzer & $\begin{array}{c}\text { LI-COR } \\
\text { Biosciences/LI-7500 }\end{array}$ & $\begin{array}{l}\text { Water vapor and } \\
\text { carbon dioxide } \\
\text { concentrations }\end{array}$ \\
\hline & $\begin{array}{c}\text { Temperature-relative } \\
\text { humidity sensor/HMP45AC }\end{array}$ & Vaisala/HMP45AC & $\begin{array}{l}\text { Air temperature and } \\
\text { relative humidity }\end{array}$ \\
\hline & 4-component net radiometer & Hukseflux/NR01 & $\begin{array}{l}\text { Incoming and outgoing } \\
\text { short-wave and long- } \\
\text { wave radiation }\end{array}$ \\
\hline \multirow{5}{*}{ CR Pavement } & Rain gauge & Davis & Rainfall \\
\hline & Radiometer & Davis/06450 & Solar radiation \\
\hline & Cup anemometer & Davis/06410 & Wind velocity \\
\hline & $\begin{array}{l}\text { Temperature/humidity } \\
\text { sensor/EHT-SS1 }\end{array}$ & Decagon/EHT-SS-1 & Air temperature \\
\hline & Infrared temperature sensor & ZyTemp & $\begin{array}{l}\text { Surface temperature } \\
\text { and soil temperature }\end{array}$ \\
\hline ESRL/PHX & Radiosonde & NOAA/ESRL & $\begin{array}{l}\text { Vertical distributions } \\
\text { of temperature, } \\
\text { humidity, and winds }\end{array}$ \\
\hline
\end{tabular}


Table 3. The urban surface and atmospheric conditions of 30 different landscaping scenarios

\begin{tabular}{|c|c|c|c|c|c|c|c|c|c|c|}
\hline $\begin{array}{c}\text { Case } \\
\#\end{array}$ & $\begin{array}{c}f_{g} \\
(\%)\end{array}$ & $\begin{array}{l}R_{t} \\
(\mathrm{~m})\end{array}$ & $\begin{array}{l}\text { Max } \\
T_{\text {can }} \\
\left({ }^{\circ} \mathrm{C}\right)\end{array}$ & $\begin{array}{c}\text { Max } q_{\text {can }} \\
\left(\times 10^{-3} \mathrm{~kg}\right. \\
\left.\mathrm{kg}^{-1}\right)\end{array}$ & $\begin{array}{c}\text { Mean } \\
H_{s} \\
(\mathrm{~W} \\
\left.\mathrm{m}^{-2}\right)\end{array}$ & $\begin{array}{c}\text { Mean } \\
L E_{s} \\
(\mathrm{~W} \\
\left.\mathrm{m}^{-2}\right)\end{array}$ & $\begin{array}{l}\text { Max } \\
\text { THI } \\
\left({ }^{\circ} \mathrm{C}\right)\end{array}$ & $\begin{array}{c}\operatorname{Max} \\
\theta_{v} \\
(\mathrm{~K})\end{array}$ & $\begin{array}{c}\operatorname{Max} q \\
\left(\times 10^{-3} \mathrm{~kg}\right. \\
\left.\mathrm{kg}^{-1}\right)\end{array}$ & $\begin{array}{c}\operatorname{Max} \\
Z_{h} \\
(\mathrm{~m})\end{array}$ \\
\hline S1 & 0 & 0 & 46.0 & 4.2 & 226.7 & 0.0 & 28.7 & 292.3 & 5.0 & 1831 \\
\hline S2 & 10 & 0 & 44.8 & 5.7 & 212.1 & 21.5 & 28.1 & 292.0 & 5.1 & 1775 \\
\hline S3 & 20 & 0 & 43.8 & 7.1 & 201.3 & 41.5 & 27.7 & 291.8 & 5.3 & 1733 \\
\hline S4 & 30 & 0 & 42.8 & 9.9 & 189.7 & 59.7 & 27.2 & 291.5 & 5.4 & 1687 \\
\hline S5 & 40 & 0 & 41.9 & 13.6 & 180.6 & 76.1 & 26.8 & 291.3 & 5.6 & 1650 \\
\hline S6 & 50 & 0 & 41.0 & 16.5 & 172.9 & 89.0 & 26.4 & 291.1 & 5.7 & 1617 \\
\hline S7 & 0 & 0.5 & 42.7 & 4.2 & 188.0 & 0.0 & 27.2 & 291.5 & 5.0 & 1680 \\
\hline S8 & 10 & 0.5 & 41.9 & 8.5 & 181.4 & 19.2 & 26.8 & 291.3 & 5.1 & 1653 \\
\hline S9 & 20 & 0.5 & 40.8 & 12.6 & 172.4 & 34.3 & 26.3 & 291.1 & 5.3 & 1615 \\
\hline $\mathrm{S} 10$ & 30 & 0.5 & 40.0 & 14.8 & 166.7 & 47.9 & 26.0 & 291.0 & 5.4 & 1591 \\
\hline S11 & 40 & 0.5 & 39.1 & 16.8 & 161.6 & 58.3 & 25.6 & 290.9 & 5.5 & 1569 \\
\hline $\mathrm{S} 12$ & 50 & 0.5 & 38.4 & 20.3 & 158.1 & 66.3 & 25.3 & 290.8 & 5.5 & 1553 \\
\hline S13 & 0 & 1 & 39.7 & 4.2 & 167.3 & 0.0 & 25.8 & 291.0 & 5.0 & 1593 \\
\hline S14 & 10 & 1 & 38.7 & 18.2 & 157.1 & 15.9 & 25.4 & 290.8 & 5.1 & 1549 \\
\hline S15 & 20 & 1 & 38.0 & 22.8 & 157.1 & 25.6 & 25.1 & 290.8 & 5.2 & 1549 \\
\hline S16 & 30 & 1 & 37.1 & 25.4 & 155.1 & 31.8 & 24.7 & 290.7 & 5.3 & 1540 \\
\hline S17 & 40 & 1 & 36.7 & 26.6 & 154.2 & 36.8 & 24.5 & 290.7 & 5.3 & 1536 \\
\hline $\mathrm{S} 18$ & 50 & 1 & 36.5 & 27.3 & 153.7 & 40.5 & 24.4 & 290.7 & 5.3 & 1534 \\
\hline S19 & 0 & 1.5 & 36.7 & 4.2 & 160.0 & 0.0 & 24.5 & 290.8 & 5.0 & 1562 \\
\hline S20 & 10 & 1.5 & 35.2 & 21.4 & 151.5 & 9.8 & 23.8 & 290.6 & 5.1 & 1524 \\
\hline $\mathrm{S} 21$ & 20 & 1.5 & 34.7 & 23.0 & 152.8 & 14.3 & 23.6 & 290.7 & 5.1 & 1530 \\
\hline S22 & 30 & 1.5 & 34.2 & 25.0 & 153.3 & 16.9 & 23.4 & 290.7 & 5.1 & 1532 \\
\hline S23 & 40 & 1.5 & 33.9 & 26.0 & 153.4 & 18.8 & 23.3 & 290.7 & 5.1 & 1532 \\
\hline S24 & 50 & 1.5 & 33.8 & 27.4 & 153.3 & 20.6 & 23.2 & 290.7 & 5.2 & 1532 \\
\hline S25 & 0 & 2 & 34.4 & 4.2 & 157.6 & 0.0 & 23.4 & 290.8 & 5.0 & 1551 \\
\hline S26 & 10 & 2 & 33.2 & 20.3 & 153.4 & 5.6 & 22.9 & 290.7 & 5.0 & 1533 \\
\hline S27 & 20 & 2 & 32.7 & 22.7 & 152.1 & 8.0 & 22.7 & 290.7 & 5.0 & 1527 \\
\hline S28 & 30 & 2 & 32.3 & 25.0 & 152.1 & 8.8 & 22.6 & 290.7 & 5.0 & 1527 \\
\hline S29 & 40 & 2 & 32.1 & 26.9 & 152.4 & 9.2 & 22.5 & 290.7 & 5.1 & 1528 \\
\hline S30 & 50 & 2 & 31.9 & 28.0 & 152.4 & 9.4 & 22.4 & 290.7 & 5.1 & 1528 \\
\hline
\end{tabular}


Table 4. Comparison of urban surface and atmospheric conditions between $0 \%$ grass and $50 \%$ grass with different tree crown radius

\begin{tabular}{|c|c|c|c|c|c|c|c|c|}
\hline & $\begin{array}{c}\Delta \max T_{c a n} \\
\left({ }^{\circ} \mathrm{C}\right)\end{array}$ & $\begin{array}{c}\Delta \max q_{\text {can }} \\
\left(\times 10^{-3} \mathrm{~kg}\right. \\
\left.\mathrm{kg}^{-1}\right)\end{array}$ & $\begin{array}{c}\Delta \text { mean } H_{s} \\
\left(\mathrm{~W} \mathrm{~m}^{-2}\right)\end{array}$ & $\begin{array}{c}\triangle \mathrm{mean} L E_{s} \\
\left(\mathrm{~W} \mathrm{~m}^{-2}\right)\end{array}$ & $\begin{array}{c}\Delta \max T H I \\
\left({ }^{\circ} \mathrm{C}\right)\end{array}$ & $\begin{array}{c}\Delta \max \theta_{v} \\
(\mathrm{~K})\end{array}$ & $\begin{array}{c}\Delta \max q \\
\left(\times 10^{-3} \mathrm{~kg}\right. \\
\left.\mathrm{kg}^{-1}\right)\end{array}$ & $\begin{array}{c}\Delta \mathrm{maxz}_{h} \\
(\mathrm{~m})\end{array}$ \\
\hline S6 - S1 & -5.0 & 12.3 & -53.8 & 89.0 & -2.2 & -1.2 & 0.7 & -213 \\
\hline $\mathrm{S} 12-\mathrm{S} 7$ & -4.3 & 16.1 & -29.9 & 66.3 & -1.9 & -0.7 & 0.6 & -126 \\
\hline S18 - S13 & -3.3 & 23.1 & -13.6 & 40.5 & -1.5 & -0.3 & 0.3 & -59 \\
\hline S24 - S19 & -2.9 & 23.2 & -6.6 & 20.6 & -1.2 & -0.2 & 0.2 & -29 \\
\hline $\mathrm{S} 30-\mathrm{S} 25$ & -2.5 & 23.8 & -5.2 & 9.4 & -1.1 & -0.1 & 0.1 & -23 \\
\hline
\end{tabular}

